\title{
Relation between Nutritional Status and Chronic Diseases among Elderly at Assiut City
}

\author{
Saieda Abd Elhameed AbdElaziz ${ }^{1}$, Shimaa Hassan Abd-Elfatah ${ }^{2}$, Naglaa Saad Abd El-aty ${ }^{3}$ \& Shimaa \\ Elwardany Aly ${ }^{4}$. \\ 1. Lecturer, Gerontological Nursing, Faculty of Nursing, Assiut University, Egypt. \\ 2. Lecturer, Gerontological Nursing, Faculty of Nursing- Sohag University, Egypt. \\ 3. \& 4 Assistant Professor of Community Health Nursing, Faculty of Nursing, Assiut University, Egypt.
}

\begin{abstract}
The occurrence of chronic diseases weakens the activity of the elderly and affects the nutritional status which exposes them to the risk of malnutrition as a result of poor health. The study aimed to assess the relation between nutritional status and chronic diseases among elderly at Assiut City. Subject and method: Descriptive cross sectional research design, Convenient sample were used in this study. The study was conducted on 1033 patients in outpatients' clinics at main Assiut university hospital. The study included two tools; the first included sociodemographic, medical history, nutritional habits and oral health, while the second mini-nutritional assessment scale. Results: $59.5 \%$ of the studied sample suffering from hypertension, while $36.5 \%, 37.4 \%$ of them had diabetes mellitus and orthopedic diseases respectively, and $65.1 \%$ of studied sample had mild Charlson Comorbidity Index (CCI). Also $63.1 \%$ of studied sample at risk for malnutrition, and $30.7 \%$ were well-nourished. The study concluded that There were a significant relation between mini-nutritional assessment scale and different chronic diseases. The study Recommended that: Establish periodically nutritional assessment of elderly to identify at risk by using MiniNutritional Assessment scale and develop continuous health education program for elderly and their caregiver about nutritional need specifically with chronic diseases.
\end{abstract}

\section{Keywords: Chronic Diseases, Elderly, \& Nutritional Status.}

\section{Introduction}

An older individual is usually described as someone elderly sixty five years or older. An elderly patient isn't always especially age-described however rather characterized by way of an excessive of frailty and multiple diseases which will become common among elderly above 80years. Because of acute and/or chronic sickness in combination with age-related degenerative changes, limitations in physical, intellectual and/or social capabilities arise. The capacity to perform the simple activities of day by day living independently is decreased or lost. (Volkert et al., 2019).

Chronic diseases are long-term period and may additionally result from a combination of genetic, physiological, environmental, and behavioral elements. The main forms of chronic disease consist of cardiovascular diseases (which account for 17.9 million deaths globally each year), cancers (which are responsible liable for nine million deaths annually), chronic respiratory diseases (about four million deaths/year), and diabetes (1.6 million deaths/year). An elderly surviving into overdue life suffer from excessive rates of chronic illness; $80 \%$ have at the least one and $50 \%$ had at the least two chronic diseases (Shaheen et al., 2017 \& Ojo, 2019).

These chronic conditions may affect appetite, functional ability or ability to swallow, all leading to altered food intake and impairment of nutritional status. Medications used in the treatment of chronic illness can also have a detrimental effect on nutritional status through loss of appetite, nausea, diarrhea, reduced gastrointestinal motility and dry mouth (Shlisky et al., 2017).

Strategies for handling these chronic diseases are typically multidimensional, and at the center of those approaches are nutritional and/or dietary interventions, ordinary physical activity, and life-style modifications. The role of nutrition in chronic disease control is particularly crucial as weight loss plan is a modifiable risk factor for most chronic diseases that exist either as unmarried diseases or in comorbid states (WHO, 2018 \& Bangkok, 2019).

The populace of Egypt is going through serious problems with a double burden of malnutrition with continual excessive stages of under nutrition and micronutrient deficiencies now combined with rapidly growing problems of over nutrients and obesity. Over nutrition results in increased dangers of obesity, heart diseases, diabetes and numerous different Non-Communicable Diseases (NCDs), and this fact is already affecting the health care needs and expenses in Egypt. Malnutrition is consequently a major cause of poverty, but poverty also leads to malnutrition (Ministry of Health \& Population, 2017). 
Elderly people need more care and assistance because of the physiological and psychological changes that occur following aging, so that improving the nutritional status of older humans performs a critical role in improving their health status and reducing the chance of chronic disease- related morbidity and mortality (Shahabi et al., 2019).

A crucial strategy for maintaining older human beings healthy is preventing chronic diseases and reducing associated complications, consisting of malnutrition. To help with nutritional adjustments and transference of information, nutrition education programs need to develop focused on older people (Turconi, 2011). The nurses must pick out the older people dietary needs and integrate the nutrition message within people's dwelling context and background. Thus, it will help older humans to remain independent longer, enhance their nutritional status and quality of life, potentially delay the want for long- time period care, slow the expected growth of health care and longtime period expenses for this and future generations (Abdelwahed et al., 2018).

\section{Significant of the Research}

Adequate nutrition can prevent and delay the severity of chronic diseases that affect elder people human beings. (Abdelrahman \& Elawam 2014). Skokowska et al., (2015) who conducted study about relation between the nutritional status of surgically treated elderly patients and selected chronic diseases and reported that $80.7 \%$ of the respondents had the proper nutritional status and $19.3 \%$ of them had at risk of malnutrition.

In Egypt carried study by Abdel-Rahman et al., (2012) who found that obesity is significantly more prevalent among elderly with hypertension and osteoarthritis $(60.3 \%, 41.2 \%$ respectively) while overweight with more significantly prevalent among diabetic (44.0\%) and there is a significant relation between being overweight or obese and associated comorbidities in studied groups. So the present study aimed to assess the relation between nutritional status and chronic diseases among elderly.

\section{Research aim}

To assess the relation between nutritional status and chronic diseases among elderly at Assiut City

\section{Research questions}

- What are the levels of nutritional status among elderly with chronic diseases?

- Is there relation between nutritional status and chronic diseases among elderly at Assiut City?

\section{Subject and Methods}

\section{Research Design}

Descriptive cross sectional research design was used in this study.

\section{Setting}

The study was carried out in outpatients clinics at main Assiut university hospital-Assiut Governorate; It was included the following clinics; Medical, Cardiac, Diabetes, Chest, Neurology, Orthopedic; which are the main largest clinics for receives cases of patients from Assiut urban and rural area which are near to Assuit Governorate and dealing with chronic disease .

Sampling

Sample size: The total number of older patients attending in the selected pervious clinics at main Assiut university hospital in the previous six months from July to December/2018 was 7030; the sample size was calculated by using Epi-info version 3.3with expected frequency of $50 \%$ and confidence level $99.9 \%$; the estimated sample size was (939); to avoid dropout and refuse the sample size increased about $10 \%$ expand to become (1033); it included about $15 \%$ from each selected clinics.

\section{Inclusion criteria}

- Elderly can be able to communicate

- Free from cognitive or psychological disorders

\begin{tabular}{|l|l|l|}
\hline Outpatient Clinics & $\begin{array}{l}\text { Attendance } \\
\text { Number of } \\
\text { Patients within } \\
(6) \text { months }\end{array}$ & $\begin{array}{l}\text { Sample size } \\
\mathbf{1 5 \% \quad \text { from }} \\
\text { total sample } \\
\text { size of each } \\
\text { Clinic) }\end{array}$ \\
\hline Medical Clinic & 720 & 108 \\
\hline Cardiac Clinic & 1320 & 198 \\
\hline Diabetic Clinic & 790 & 119 \\
\hline Chest Clinic & 600 & 90 \\
\hline $\begin{array}{l}\text { Neurological } \\
\text { Clinic }\end{array}$ & 1200 & 180 \\
\hline Orthopedic Clinic & 2400 & 360 \\
\hline Total & $\mathbf{7 0 3 0}$ & $\mathbf{1 0 3 3}$ \\
\hline
\end{tabular}

The following table cleared the number of elderly in each clinic

Sample technique: Convenient sample was used in the present study.

Tools of data collection:

Two proper tools were included in this study after reviewing the relevant literature to elicit information;

Tool I: the researchers design interview questionnaire sheet which divided into four parts;

Part (1): Socio-demographic characteristics of participants; it included sex, age, current job, level of education, marital status and residence.

Part (2): Medical history of participants about chronic diseases; it included type of disease and duration, and types of medication used. The risk of mortality and burden of disease was estimated by using Charlson Comorbidity Index(CCI); this scale was developed by (Charlson et al., 1987) and modified by (Schneeweiss et al., 2003). 
CCI score, the severity of comorbidity was categorized into three grades: mild, with CCI scores of 1-2; moderate, with CCI scores of 3-4; and severe, with CCI scores $\geq 5$.

Part (3): Nutritional habits; it included number of meal per day, basic meal, type of food, prefers to have special food and specific habits.

Part (4): Oral health problems; it included types of teeth, presence of oral health problems (oral dryness, bleeding, oral lesion, teeth decay and teeth loss, sensitivity and swallowing problems).

Tool II: Mini Nutritional Assessment scale (MNA), this scale was developed by Rubenstein et al., 2001. It was consisted of 18 questions; the first 6 question (screening) and the second 12 questions (Assessment) to assess nutritional status among elderly; for total score the scale contained 30 points. A score of 24 to 30 which indicated to normal nutritional status, from 17 to 23.5 points indicated to at risk of malnutrition and less than 17 points indicated to malnourished.

\section{Validity of the tools}

The tools were transferred to Arabic language and reviewed to ascertain their validity by five experts in nursing sciences who reviewed the tools for clarity, relevance, comprehensiveness, understanding and applicability according to the opinions of the experts the modification was done.

Reliability of the tool: tool II (Mini-nutritional assessment), was assessed by using alpha-Cronbach test to test the internal consistency was Alpha $=0.814$.

\section{Methodology \\ Dministrative Phase}

An official approval letter was obtained from the Dean of the Faculty of Nursing at Assiut University to the director of outpatients clinics at main Assiut university hospital; this letter was containing brief explanations of the purpose of study and a permission to apply the study.

\section{Pilot study}

A pilot study was applied before beginning of data gathering on $103(10 \%)$ of the participants which included in the study sample for non-presence any modification. The purpose of the pilot study was to ensure the clarity of items and their comprehension applicability and relevance of the tools, in addition to identify obstacles and problems that may be occurring during data collection; also to test wording questions and estimate the time that required to collections of study sample.

\section{Ethical Consideration}

- The research proposal was approved from ethical committee in the Faculty of Nursing at Assuit University.
- There was no risk for study subject during application of research,

- The study followed the common ethical principles in clinical research,

- Informed consent was obtained from participants that were participated in the study after explaining the nature and purpose of the study,

- Confidentiality and anonymity was assured and study participants have the right to refuse to participate or withdraw from the study.

Field work

- Data was gathered from the previously mentioned setting from the period of beginning April/2019 to the end of Septembers /2019.

- The researchers first introduced themselves for the participants, explained the purpose of the study and getting their oral consent.

- After that the researchers started filling the sheet by face to face individual interview.

- The average time taken for completing the questionnaire was around 20-30 minutes or more depending on the personnel responding to a question.

- It's consumed around 6 months through two days weekly for collecting the questionnaire sheet; every week about (42) sheets were collected.

\section{Statistical analysis}

Data entry and data analysis were done using SPSS version 22 (Statistical Package for Social Science). Data were presented as number, percentage, mean, standard deviation and median. Chi-square test was used to compare between qualitative variables. Pvalue considered statistically significant when $\mathrm{P}<$ 0.05 . 


\section{Results}

Table (1): Distribution of studied sample according to socio- demographic characteristics in outpatients clinics at Assiut city, 2019 ( $\mathrm{No}=\mathbf{1 0 3 3}$ ).

\begin{tabular}{|c|c|c|}
\hline Socio-demographic characteristics. & No. & $\%$ \\
\hline \multicolumn{3}{|l|}{ Sex: } \\
\hline Male & 561 & 54.3 \\
\hline Female & 472 & 45.7 \\
\hline \multicolumn{3}{|l|}{ Age: (years) } \\
\hline $65-<75$ & 836 & 80.9 \\
\hline $75-<85$ & 136 & 13.2 \\
\hline$\geq 85$ & 61 & 5.9 \\
\hline Mean \pm SD (Range) & \multicolumn{2}{|c|}{$67.38 \pm 8.10(60.0-97.0)$} \\
\hline \multicolumn{3}{|l|}{ Current job: } \\
\hline Farmer & 69 & 6.7 \\
\hline Skilled worker & 117 & 11.3 \\
\hline Professional & 394 & 38.1 \\
\hline Free business & 118 & 11.4 \\
\hline Retired & 142 & 13.7 \\
\hline Not work & 193 & 18.7 \\
\hline \multicolumn{3}{|l|}{ Level of education: } \\
\hline Illiterate & 277 & 26.8 \\
\hline Read \& write & 187 & 18.1 \\
\hline Basic education & 208 & 20.1 \\
\hline Secondary & 218 & 21.1 \\
\hline University & 143 & 13.8 \\
\hline \multicolumn{3}{|l|}{ Marital status: } \\
\hline Married & 932 & 90.2 \\
\hline Divorced & 13 & 1.3 \\
\hline Widowed & 70 & 6.8 \\
\hline Single & 18 & 1.7 \\
\hline \multicolumn{3}{|l|}{ Residence: } \\
\hline Rural & 595 & 57.6 \\
\hline Urban & 438 & 42.4 \\
\hline
\end{tabular}

Table (2): Distribution of the studied sample according to chronic diseases and its duration in outpatients clinics at Assiut city, 2019 (No=1033).

\begin{tabular}{|l|c|c|}
\hline \multicolumn{1}{|c|}{ Items } & No. & \% \\
\hline Chronic diseases: & 377 & $\mathbf{3 6 . 5}$ \\
\hline Diabetes mellitus & 615 & $\mathbf{5 9 . 5}$ \\
\hline Hypertension & 251 & 24.3 \\
\hline Neurological diseases & 122 & 11.8 \\
\hline Liver diseases & 358 & 34.7 \\
\hline Respiratory diseases & 158 & 15.3 \\
\hline Cardiac diseases & 66 & 6.4 \\
\hline Kidney diseases & 14 & 1.4 \\
\hline Thyroid disorders & 386 & $\mathbf{3 7 . 4}$ \\
\hline Orthopedic diseases & 342 & 33.1 \\
\hline Duration of chronic diseases: & 376 & 36.4 \\
\hline$<5$ & 315 & 30.5 \\
\hline $5-<10$ & \multicolumn{2}{|}{} \\
\hline$\geq 10$ & \multicolumn{2}{|c|}{} \\
\hline
\end{tabular}




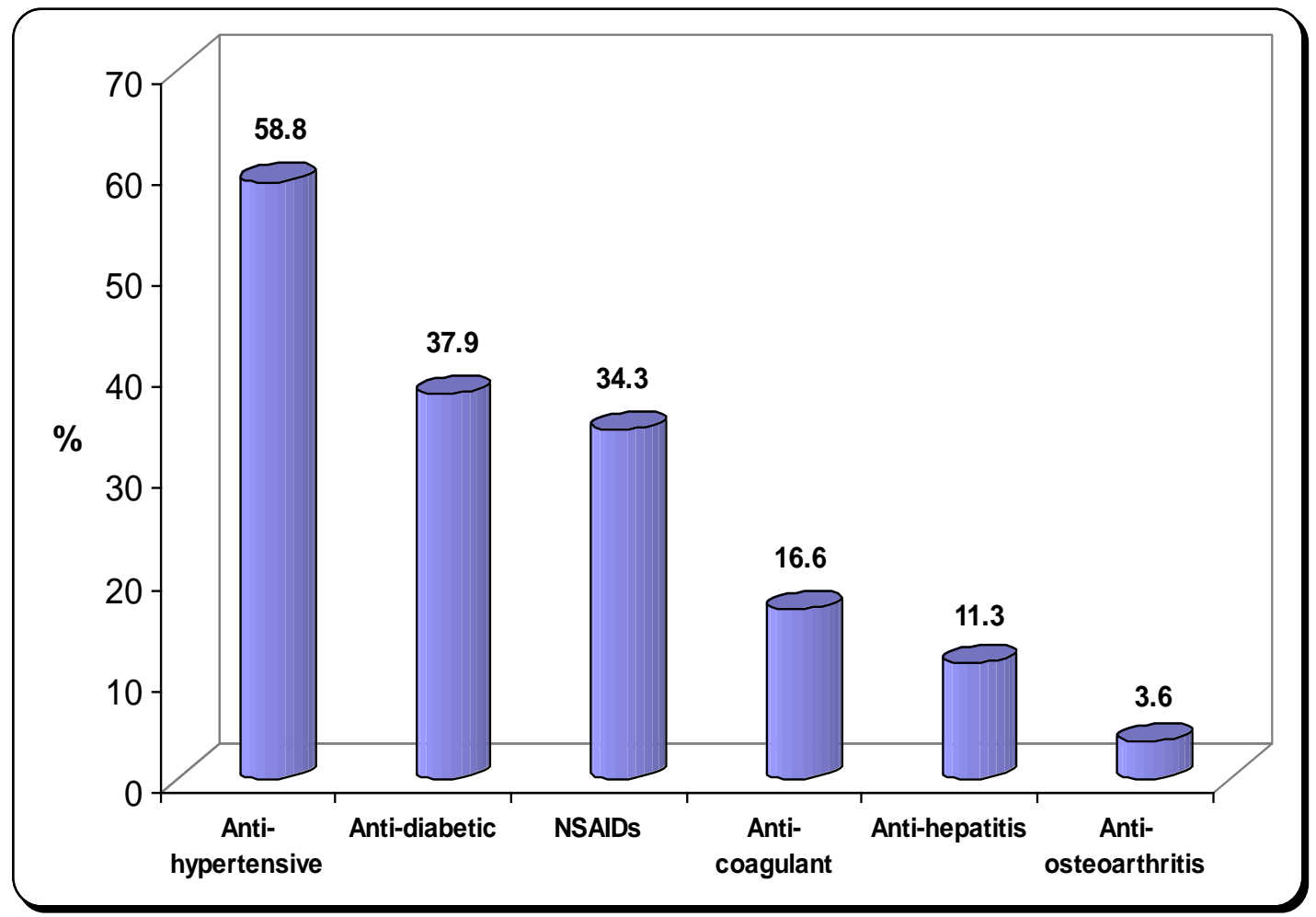

Figure (1): Distribution of the studied sample according to types of medication used in outpatients clinics at Assiut city, 2019 (No=1033).

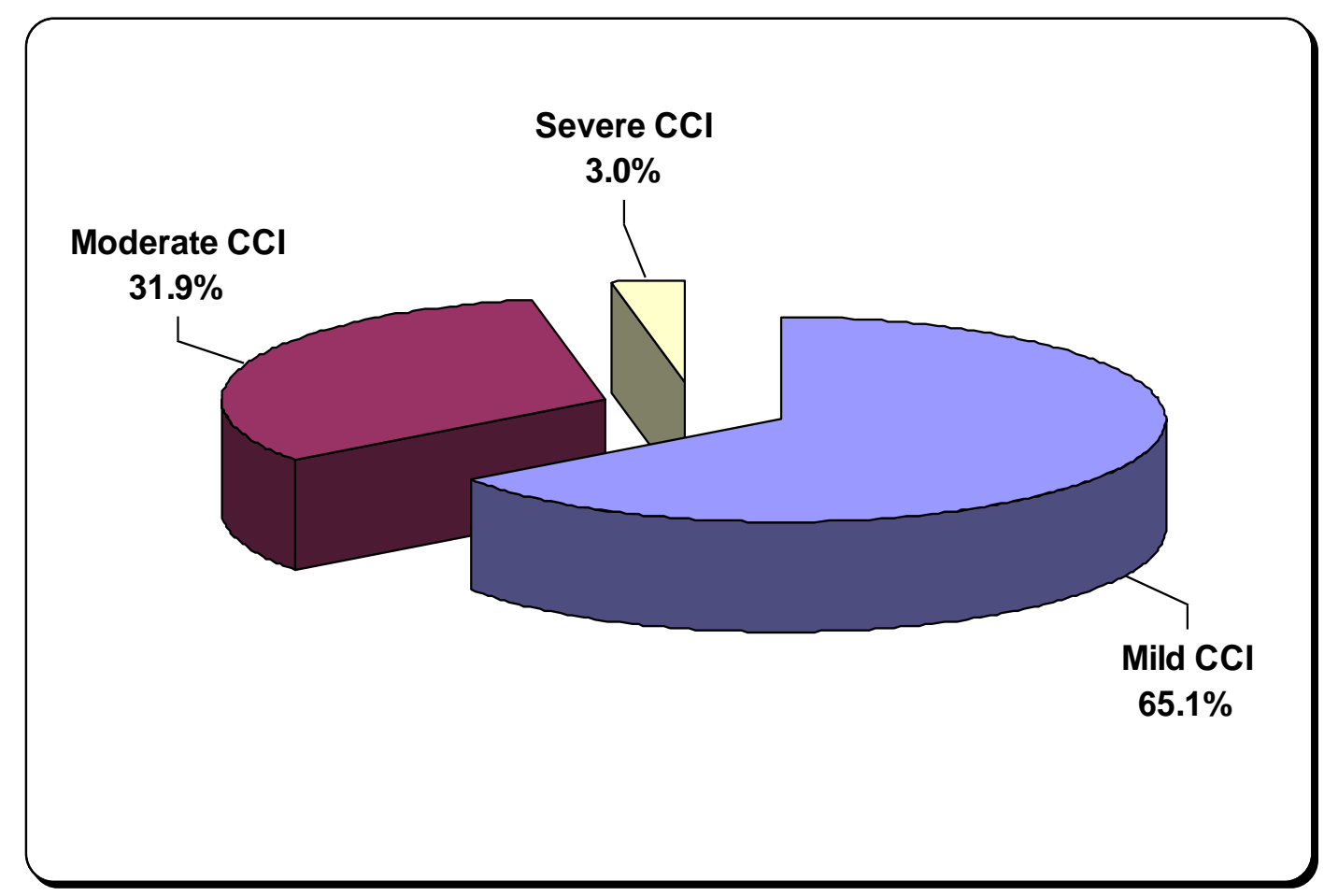

Figure (2): Distribution of the studied sample according to Charlson Co morbidity Index (CCI) in outpatients clinics at Assiut city, 2019 ( $\mathrm{No}=1033)$. 
Table (3): Distribution of studied sample according nutritional habits in outpatients clinics at Assiut city, 2019 (No=1033).

\begin{tabular}{|l|c|c|}
\hline \multicolumn{1}{|c|}{ Items } & No. & \% \\
\hline Number of meal per day: & 14 & 1.4 \\
\hline Two & 946 & $\mathbf{9 1 . 6}$ \\
\hline Three & 35 & 3.4 \\
\hline Four & 38 & 3.7 \\
\hline Five or more & 973 & $\mathbf{9 4 . 2}$ \\
\hline Basic meal: & 58 & 5.6 \\
\hline Breakfast & 2 & 0.2 \\
\hline Lunch & \multicolumn{2}{|c|}{} \\
\hline Dinner & 881 & $\mathbf{8 5 . 3}$ \\
\hline Type of food: & 152 & 14.7 \\
\hline From the same family food & 2 & 1.3 \\
\hline Prepare special food (therapeutic food) & 150 & 98.7 \\
\hline Prefer to have you special food: & 491 & 47.5 \\
\hline Yes & 82 & $\mathbf{2 6 . 5}$ \\
\hline No & 274 & 18.0 \\
\hline Special habits that affecting on the health: & 186 & \\
\hline No habits & \multicolumn{2}{|l|}{} \\
\hline Smoking &
\end{tabular}

Table (4): Distribution of the studied sample according oral health in outpatients clinics at Assiut city, 2019 (No=1033).

\begin{tabular}{|c|c|c|}
\hline Items & No. & $\%$ \\
\hline \multicolumn{3}{|l|}{ Types of teeth } \\
\hline Natural & 893 & 86.4 \\
\hline Artificial & 140 & 13.6 \\
\hline \multicolumn{3}{|l|}{ Oral health problems } \\
\hline Oral dryness & 751 & $\mathbf{7 2 . 7}$ \\
\hline Bleeding & 445 & 43.1 \\
\hline Teeth decay and teeth loss & 620 & 60.0 \\
\hline Oral lesion & 22 & 2.1 \\
\hline Teeth sensitivity & 374 & 36.2 \\
\hline Swallowing problems & 360 & 34.8 \\
\hline
\end{tabular}


Table (5) Distribution of the studied sample according Mini Nutritional Assessment scale in outpatients clinics at Assiut city, 2019 (No=1033).

\begin{tabular}{|c|c|c|}
\hline Items & No. & $\%$ \\
\hline \multicolumn{3}{|c|}{$\begin{array}{l}\text { Has the lack of eating during the past three months resulted from anorexia, digestion problems, and } \\
\text { difficulties with chewing or swallowing? }\end{array}$} \\
\hline Severe anorexia & 6 & 0.6 \\
\hline Moderate anorexia & 276 & 26.7 \\
\hline No loss of appetite & 751 & 72.7 \\
\hline \multicolumn{3}{|c|}{ The extent of weight loss during the last three months: } \\
\hline Weight loss more than 3 kilo & 12 & 1.2 \\
\hline Unknown & 490 & 47.4 \\
\hline Weight loss ranged from 1 to 3 kilo & 29 & 2.8 \\
\hline No weight loss & 502 & 48.6 \\
\hline \multicolumn{3}{|l|}{ Mobility } \\
\hline bed or chair bound & 4 & 0.4 \\
\hline able to get out of bed / chair but does not go out & 117 & 11.3 \\
\hline goes out & 912 & 88.3 \\
\hline \multicolumn{3}{|l|}{ Any stress or severe illness in the past three months: } \\
\hline No & 425 & 41.1 \\
\hline Yes & 608 & 58.9 \\
\hline \multicolumn{3}{|l|}{ Neurological and psychological problems: } \\
\hline Severe senile dementia or depression & 0 & 0.0 \\
\hline Moderate dementia & 104 & 10.1 \\
\hline No & 929 & 89.9 \\
\hline
\end{tabular}

Continue Table (5) Distribution of the studied sample according Mini Nutritional Assessment scale in outpatients clinics at Assiut city, 2019 (No=1033).

\begin{tabular}{|c|c|c|}
\hline Items & No. & $\%$ \\
\hline \multicolumn{3}{|l|}{ Body mass index: (BMI) } \\
\hline Underweight & 124 & 12.0 \\
\hline Normal weight & 317 & 30.7 \\
\hline Overweight & 245 & 23.7 \\
\hline Obese & 347 & 33.6 \\
\hline \multicolumn{3}{|c|}{ Live independently(not in nursing home or hospital): } \\
\hline No & 15 & 1.5 \\
\hline Yes & 1018 & 98.5 \\
\hline \multicolumn{3}{|c|}{ Taking more than three prescription drugs per day: } \\
\hline No & 605 & 58.6 \\
\hline Yes & 428 & 41.4 \\
\hline \multicolumn{3}{|c|}{ Suffering from bed sores or skin ulcer: } \\
\hline No & 945 & 91.5 \\
\hline Yes & 88 & 8.5 \\
\hline \multicolumn{3}{|l|}{ Leg circumference: } \\
\hline$<31 \mathrm{~cm}$ & 478 & 46.3 \\
\hline$\geq 31 \mathrm{~cm}$ & 555 & 53.7 \\
\hline
\end{tabular}


Continue Table (5) Distribution of the studied sample according Mini Nutritional Assessment scale in outpatients clinics at Assiut city, 2019 ( $\mathrm{No}=1033)$.

\begin{tabular}{|c|c|c|}
\hline Items & No. & $\%$ \\
\hline \multicolumn{3}{|l|}{ How many complete meals a patient eat daily? } \\
\hline One & 0 & 0.0 \\
\hline Two & 108 & 10.5 \\
\hline Three & 925 & 89.5 \\
\hline \multicolumn{3}{|c|}{$\begin{array}{l}\text { Selected consumption markers for protein intake } \\
\text { - At least one serving of dairy products (milk, cheese, yoghurt) per day } \\
\text { - Two or more servings of legumes or eggs per week } \\
\text { - } \quad \text { Meat, fish or poultry every }\end{array}$} \\
\hline 0 - 1 (yes answer) & 198 & 19.2 \\
\hline 2 (yes answers) & 557 & 53.9 \\
\hline 3 ( yes answers) & 278 & 26.9 \\
\hline \multicolumn{3}{|c|}{ Consume two or more servings of fruits or vegetables daily: } \\
\hline No & 140 & 13.6 \\
\hline Yes & 893 & 86.4 \\
\hline \multicolumn{3}{|c|}{ How much fluid (water, juice, coffee, tea, milk...) is consumed daily? } \\
\hline Less than 3 cups & 240 & 23.2 \\
\hline $3-5$ cups & 793 & 76.8 \\
\hline \multicolumn{3}{|l|}{ Mode of feeding: } \\
\hline Unable to eat without assistance & 24 & 2.3 \\
\hline Feeds himself with some difficulty & 220 & 21.3 \\
\hline Feeds himself without any problem & 789 & 76.4 \\
\hline \multicolumn{3}{|l|}{ Self-view of nutritional status: } \\
\hline Views self as being malnourished & 123 & 11.9 \\
\hline Uncertain of nutritional state & 568 & 55.0 \\
\hline Views self as having no nutritional problem & 342 & 33.1 \\
\hline \multicolumn{3}{|c|}{ In comparison with other people of the same age, how does the patient consider his / her health status? } \\
\hline Not as good & 236 & 22.8 \\
\hline Does not know & 469 & 45.4 \\
\hline As good & 242 & 23.4 \\
\hline Better & 86 & $8 . .3$ \\
\hline \multicolumn{3}{|l|}{ Mid arm circumference: } \\
\hline$<21 \mathrm{~cm}$ & 164 & 15.9 \\
\hline $21-22 \mathrm{~cm}$ & 360 & 34.8 \\
\hline$>22 \mathrm{~cm}$ & 509 & 49.3 \\
\hline
\end{tabular}




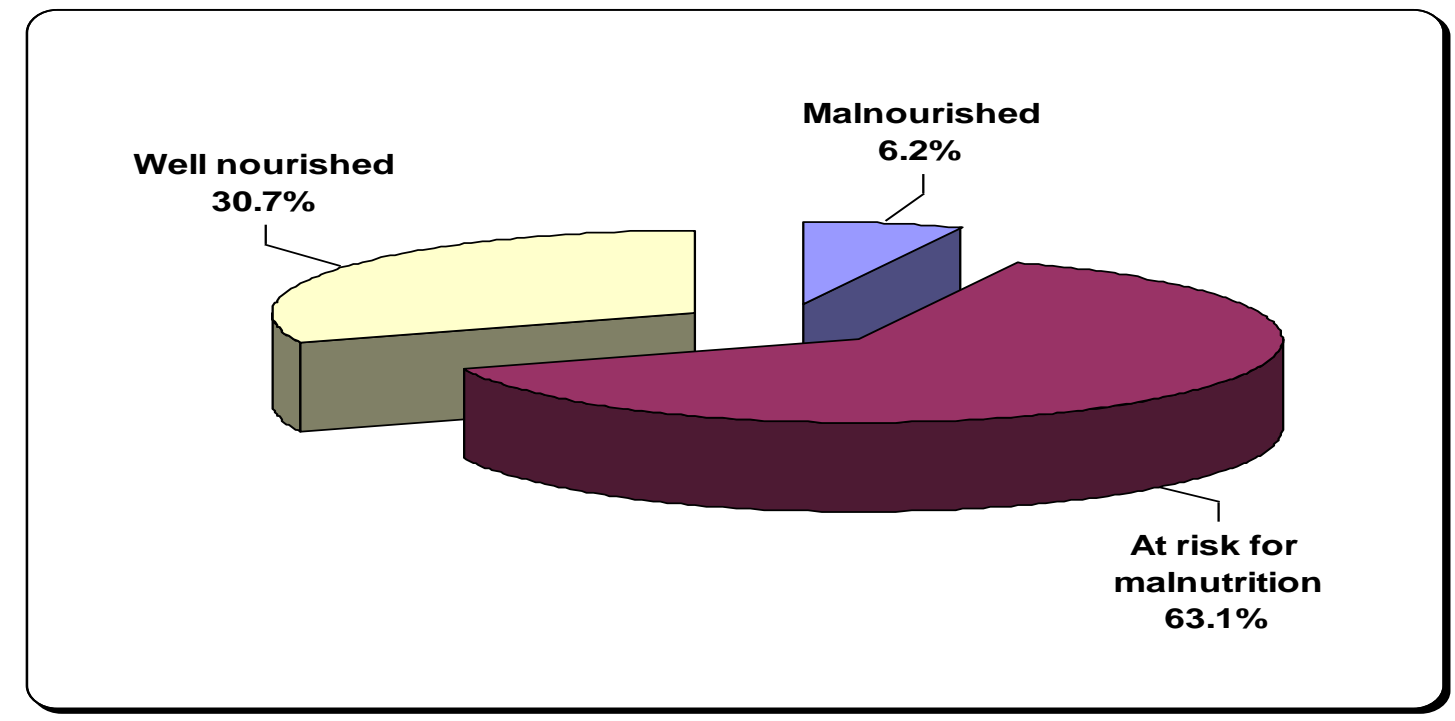

Figure (3): Mini-nutritional assessment scale among studied sample in outpatients clinics at Assiut city, 2019 $(\mathrm{No}=1033)$.

Table (6): Relationship of socio demographic characteristics with Mini-nutritional assessment scale among studied sample in outpatients clinics at Assiut city, 2019 ( $\mathrm{No}=1033$ ).

\begin{tabular}{|c|c|c|c|c|c|c|c|}
\hline \multirow{3}{*}{$\begin{array}{l}\text { Socio demographic } \\
\text { Characteristics }\end{array}$} & \multicolumn{6}{|c|}{ Mini-nutritional assessment scale } & \multirow{3}{*}{ P-value } \\
\hline & \multicolumn{2}{|c|}{$\begin{array}{c}\text { Malnourished } \\
(64)\end{array}$} & \multicolumn{2}{|c|}{$\begin{array}{c}\text { At risk for } \\
\text { Malnutrition } \\
(652)\end{array}$} & \multicolumn{2}{|c|}{$\begin{array}{l}\text { Well nourished } \\
(\mathbf{3 1 7})\end{array}$} & \\
\hline & No. & $\%$ & No. & $\%$ & No. & $\%$ & \\
\hline \multicolumn{7}{|l|}{ Sex: } & \multirow{3}{*}{0.259} \\
\hline Male & 29 & 5.2 & 363 & 64.7 & 169 & 30.1 & \\
\hline Female & 35 & 7.4 & 289 & 61.2 & 148 & 31.4 & \\
\hline \multicolumn{7}{|l|}{ Age: (years) } & \multirow{4}{*}{$0.002 *$} \\
\hline $65-<75$ & 56 & 6.7 & 530 & 63.4 & 250 & 29.9 & \\
\hline $75-<85$ & 0 & 0.0 & 84 & 61.8 & 52 & 38.2 & \\
\hline$\geq 85$ & 8 & 13.1 & 38 & 62.3 & 15 & 24.6 & \\
\hline \multicolumn{7}{|l|}{ Current job: } & \multirow{7}{*}{$0.001 *$} \\
\hline Farmer & 5 & 7.2 & 47 & 68.1 & 17 & 24.6 & \\
\hline Skilled worker & 7 & 6.0 & 95 & 81.2 & 15 & 12.8 & \\
\hline Professional & 19 & 4.8 & 228 & 57.9 & 147 & 37.3 & \\
\hline Free business & 5 & 4.2 & 84 & 71.2 & 29 & 24.6 & \\
\hline Retired & 6 & 4.2 & 80 & 56.3 & 56 & 39.4 & \\
\hline No work & 22 & 11.4 & 118 & 61.1 & 53 & 27.5 & \\
\hline \multicolumn{7}{|l|}{ Level of education: } & \multirow{6}{*}{$0.001 *$} \\
\hline Illiterate & 27 & 9.7 & 151 & 54.5 & 99 & 35.7 & \\
\hline Read \& write & 10 & 5.3 & 138 & 73.8 & 39 & 20.9 & \\
\hline Basic education & 14 & 6.7 & 144 & 69.2 & 50 & 24.0 & \\
\hline Secondary & 10 & 4.6 & 132 & 60.6 & 76 & 34.9 & \\
\hline University & 3 & 2.1 & 87 & 60.8 & 53 & 37.1 & \\
\hline \multicolumn{7}{|l|}{ Marital status: } & \multirow{3}{*}{0.053} \\
\hline Married & 53 & 5.7 & 597 & 64.1 & 282 & 30.3 & \\
\hline Unmarried & 11 & 10.9 & 55 & 54.5 & 35 & 34.7 & \\
\hline \multicolumn{7}{|l|}{ Residence: } & \multirow{3}{*}{$0.001 *$} \\
\hline Rural & 49 & 8.2 & 388 & 65.2 & 158 & 26.6 & \\
\hline Urban & 15 & 3.4 & 264 & 60.3 & 159 & 36.3 & \\
\hline
\end{tabular}


Table (7): Relationship body mass index and chronic disease among studied sample in outpatients clinics at Assiut city, 2019 (No=1033).

\begin{tabular}{|c|c|c|c|c|c|c|c|c|c|}
\hline \multirow{3}{*}{ Chronic diseases } & \multicolumn{8}{|c|}{ Body mass index (BMI) } & \multirow{3}{*}{ P-value } \\
\hline & \multicolumn{2}{|c|}{$\begin{array}{c}\text { Underweight } \\
\text { (124) }\end{array}$} & \multicolumn{2}{|c|}{$\begin{array}{c}\text { Normal } \\
(317)\end{array}$} & \multicolumn{2}{|c|}{$\begin{array}{l}\text { Overweight } \\
\text { (245) }\end{array}$} & \multicolumn{2}{|c|}{$\begin{array}{c}\text { Obese } \\
(347)\end{array}$} & \\
\hline & No. & $\%$ & No. & $\%$ & No. & $\%$ & No. & $\%$ & \\
\hline Diabetes Mellitus & 34 & 27.4 & 130 & 41.0 & 68 & 27.8 & 145 & 41.8 & $0.000 *$ \\
\hline HTN & 75 & 60.5 & 188 & 59.3 & 146 & 59.6 & 206 & 59.4 & 0.996 \\
\hline Neurology & 48 & 38.7 & 52 & 16.4 & 64 & 26.1 & 87 & 25.1 & 0.000* \\
\hline Liver diseases & 12 & 9.7 & 30 & 9.5 & 35 & 14.3 & 45 & 13.0 & 0.250 \\
\hline Respiratory diseases & 32 & 25.8 & 168 & 53.0 & 67 & 27.3 & 91 & 26.2 & 0.000* \\
\hline Cardiac diseases & 29 & 23.4 & 35 & 11.0 & 26 & 10.6 & 68 & 19.6 & $\mathbf{0 . 0 0 0 *}$ \\
\hline Kidney diseases & 8 & 6.5 & 24 & 7.6 & 13 & 5.3 & 21 & 6.1 & 0.732 \\
\hline Thyroid disorders & 1 & 0.8 & 5 & 1.6 & 4 & 1.6 & 4 & 1.2 & 0.886 \\
\hline Orthopedic diseases & 79 & 63.7 & 32 & 10.1 & 101 & 41.2 & 174 & 50.1 & 0.000* \\
\hline
\end{tabular}

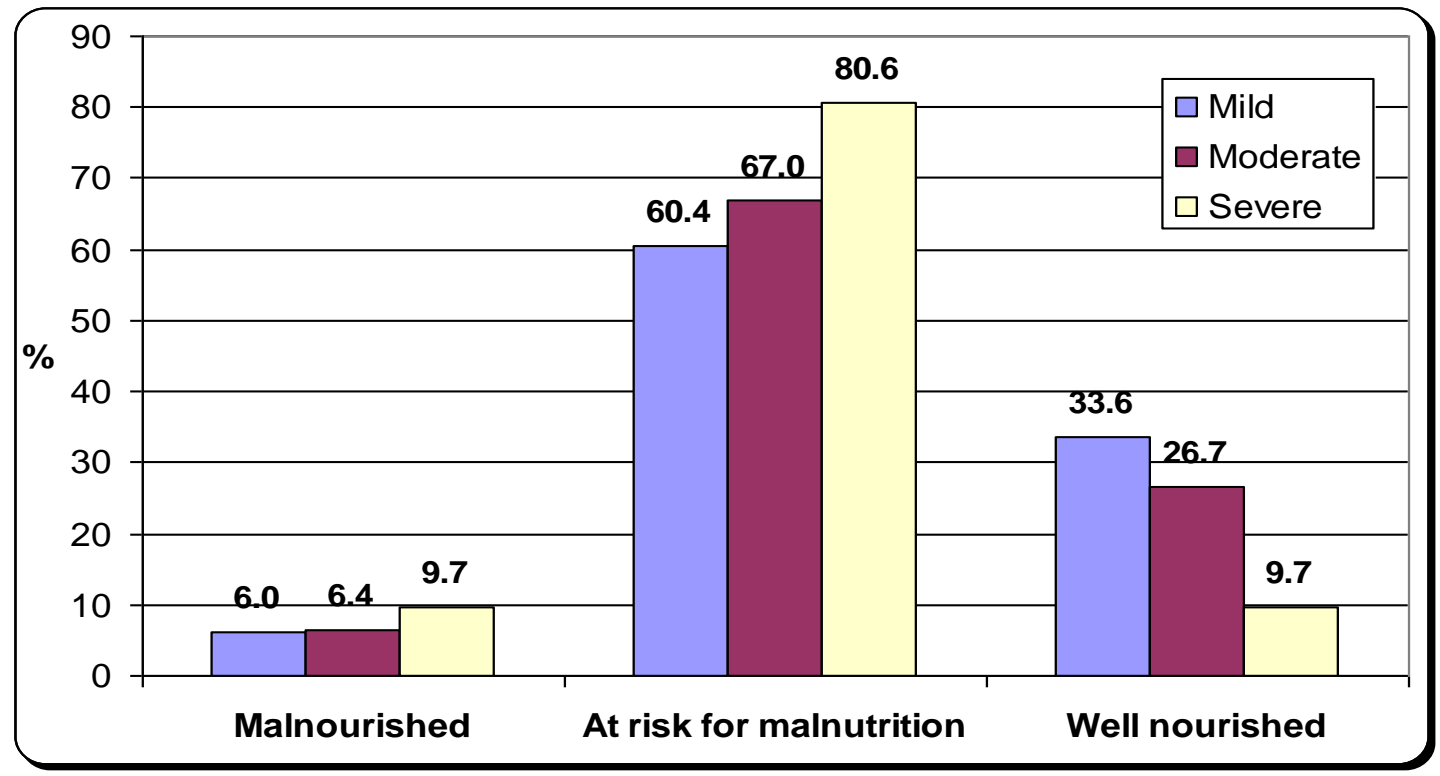

Figure (4): Relation between Mini-Nutritional Scale and CharIson Comorbidity Index (CCI) among studied sample in outpatients clinics at Assiut city, 2019 ( $\mathrm{No}=1033)$.

Table (1): Show that $80.9 \%$ of the studied sample their age ranged from $65-<75 y$ years with mean age of $67.38 \pm 8.10(60.0-97.0)$ and $54.3 \%$ of them were male. Concerning to current job, it was observed that $38.1 \%$ of the studied samples have professional job, while $13.7 \%$ of them on retired. Regarding level of education, $26.8 \%$ of them were illiterate and only $20.1 \%$ of them had basic education. As regard residence it was observed that $57.6 \%$ of them from rural area.

Table (2): Revealed that $59.5 \%$ of the studied sample suffering from hypertension, while $36.5 \%, 37.4 \%$ of them had diabetes mellitus and orthopedic diseases respectively. Regarding duration of chronic diseases it was observed that, $36.4 \%$ of them had chronic disease from5 $-<10$ years.
Figure (1): Illustrated that $58.8 \%$ and $37.9 \%$ of studied sample were used anti-hypertensive and antidiabetic drugs respectively, while $3.6 \%$ of them use anti-osteoarthritis drugs.

Figure (2): Illustrated that $65.1 \%$ of studied sample had mild CCI while $3.0 \%$ from them had severe CCI.

Table (3): Presented that $91.6 \%, 94.2 \%, 85.3 \%$ of studied sample eat three meals /day, breakfast is considering a basic meal for them and have the same family food respectively. Regarding had special habit that affecting on the health; $26.5 \%$ from them were consumption of tea and coffee.

Table (4): Revealed that $86.4 \%$ of studied sample have natural teeth and the most common oral health problems among them were oral dryness, followed 
teeth decay and teeth loss then bleeding by percentage $72.7 \%, 60.0 \%$, and $43.1 \%$ respectively.

Table (5): Cleared that $48.6 \%$ of studied sample don't have weight loss during the last three months and $88.3 \%$ of them were able to goes out. Regarding to body mass index, it was observed that $33.6 \%$ of studied sample were obese and only $12 \%$ of them were underweight. $98.5 \%$ of studied sample live independently (not in nursing home or hospital) and $41.4 \%$ of them taking more than three prescribing drugs per day.

Concerning to fruits and vegetables, it was observed that $86.4 \%$ of studied sample consumes two or more serving per /day. Also this table clears that $76.8 \%$ of them take amounts of liquids from 3-5 cups per day. Regarding mode of feeding, $76.4 \%$ of studied sample feeds their self without any problem and $33.1 \%$ of them view self as having no nutritional problem.

Figure (3): Illustrated that $63.1 \%$ of studied sample at risk for malnutrition, and only $30.7 \%$ were wellnourished while $6.2 \%$ of them were malnourished

Table (6): Showed that there were statistical significant differences between mini-nutritional assessment scale and socio demographic characteristics among studied sample for age, job, level of education, and

residence, $(\mathrm{P}$-value $=0.002,0.001,0.001$ and 0.001$)$ respectively.

Table (7): Showed that there were statistically significant difference between Body mass index and studied elderly with Diabetes Mellitus, neurology, respiratory, cardiac, and orthopedic diseases with $\mathrm{P}=$ value $\left(0.000^{*}\right)$.

Figure (4): Presented that there were statistical significant differences between mini-nutritional assessment scale and CharIson Comorbidity Index (CCI ) or chronic disease score with P-value $=0.019$.

\section{Discussion}

Nutritional status of older people results from a complex interplay between dietary, socio-economic, physical and psychological factors; nutrition is often considered the foundation of health and an important indicator of well-being. Older adults high risk for poor nutrition due to the incidence of multiple chronic diseases as well as the financial instability and social isolation that often plagues this population (Tamang et al ., 2019).

Females were more likely to be affected by malnutrition, as $7.4 \%$ of females were malnourished vs $5.2 \%$ males. These findings were in coherence with a study findings of Ghimire et al., (2017) that carried out "nutritional assessment of communitydwelling older adults in rural Nepal" and stated that malnutrition to be higher among females compared to their male counterparts; however, these findings were not significant. A reason for this maybe the effect of attention directed toward women of child-bearing age, with focus on reducing child mortality; elderly women have not yet been include as a focus. In addition to diminish access to economic resources and education Egyptian women are adversely impacted by cultural practices as well. For example, traditionally, men and children are fed first, and given them or nutritious foods, often leaving women with little or no remaining nutritious food.

Results of the current study portrays that mean of age of studied sample was $67.38 \pm 8.10$ and there significant difference between age and malnutrition; these results in same line with Abdelwahed et al ., (2018) who carried out "effect of a nutritional education program on nutritional status of elderly in rural areas of Damanhur City, Egypt" and found the participants' mean age was $69.59 \pm 7.163$, also supported by Damayanthi et al ., (2018) who carried out " Prevalence of malnutrition and associated factors among community-dwelling older persons in Sri Lanka:" and stated that there significant difference between age and malnutrition. This result may be attributed to changes associated with aging; there physiological changes directly affect the metabolism of nutrients. Also, physiological conditions of aging, such as sarcopenia and osteoporosis, might progressively limit the mobility of older individuals, further limiting their ability in shopping; preparing foods and even consuming foods.

Considering the elderly education, the present study findings claimed that their level education had a significant effect on the nutritional status. In agreement Wilma \& Hankey (2015) who carried out "aging, nutritional status and health" and mentioned that the majority of elder patients presented with nutritional inadequacies and malnutrition were of lower educational levels. This might be justified that lower level of education and limited literacy hindering elder people from access to proper nutrition and aware food choices.

Married Elderly persons who were having better nutritional health than their counterparts. This result agrees with Kucukerdonmez et al., (2017) who conducted "Comparison of nutritional status in the elderly according to living situations" and reported that married elderly, living with more family members might help older persons to prevent loneliness and social isolation which are common reasons why older persons eat more poorly. This may be due to support from family members may be crucial in nutritional interventions that aim to improve the nutritional status of older persons in the community.

Concerning of residence among studied elderly, the current study showed that malnutrition is common among elderly living in rural areas than urban area, 
this finding in same line with Jung et al., (2017) who reported that older adults residing in rural areas generally have fewer opportunities for social interaction. This is commonly due to geographic isolation and out-migration of younger adults who serve as supportive resources.

As regards chronic disease the result of current research revealed that more than half of the studied sample suffering from hypertension, while more than one third of them had diabetes mellitus and orthopedic diseases, these findings in harmony with study carried out by Khater \& Abouelezz, (2011) " Nutritional status in older adults with mild cognitive impairment living in elderly homes in Cairo, Egypt" and reported that more than one third of the elderly were diabetics, half were hypertensive, one fifth had ischemic heart disease, more than two fifths were depressed, and $16 \%$ had symptoms of osteoarthritis.

Concerning the presence of chronic illnesses and use of medication had significant impact on the elderly nutritional status, which comes in line with the findings, reported by LaBrier et al., (2017) who carried out "nutrition in older adults", and mentioned from risk factors associated with poor nutrition status among the elderly was chronic diseases and use of medication. These results explain where aging is accompanied by an increased likelihood of suffering from one or more chronic diseases; these conditions may affect appetite, functional ability or ability to swallow, all leading to altered food intake and impairment of nutritional status.

Regarding BMI, the present study revealed that the prevalence rate of obesity in the elderly who attended outpatient clinics in Assiut university hospitals was slightly more than one third (based on the WHO criteria for defining obesity). This result is in the same line with the result of another study conducted in Mansoura City in Egypt by Shebl et al., (2015) who reported prevalence of obesity was $28.3 \%$ among studied elderly. BMI categories showed statistically significant differences with the nutritional status. Also, this finding compatible with study which performed by Damayanthi et al., (2018)who carried out "Prevalence of malnutrition and associated factors among community-dwelling older persons in Sri Lanka" and reported that there was a relation between BMI and nutritional status.

Regarding loss of appetite in the last three months, this result cleared that less than three quarters of study elderly had no loss of appetite. This result disagrees with Eldardery et al., (2018) who performed "risk Factors of malnutrition among elderly in geriatric homes" and reported that less than one third of studied elderly had not loss of appetite. Concerning the perception of health status in relation to other people of the same age, result showed that more than one fifth and only $8.3 \%$ not on the same quality and Better than others respectively. These results in same line with Mahfouz et al., (2013) that carried out "Assessment of nutritional status of elderly populations in rural Minia, Egypt" and found that more than one fifth and only $3.2 \%$ not on the same quality and better than others respectively.

In the present study, according to the MNA scores received on the Mini Nutritional Assessment test, more than three fifths of the elderly had at risk for malnutrition and only $6.2 \%$ from them malnourished while less than one third well nourished. These findings agree with Damayanthi et al., (2018) who reported that $12.5 \%$ of the participants were malnourished, about half $(52.4 \%)$ were at risk of malnutrition and one-third $(35.1 \%)$ were wellnourished. These results may be due to more than two fifths of the study sample had basic and secondary education.

However, there were contradictory findings on studies of Mahfouz et al., (2013) who reported that $8.6 \%$ of the elderly were malnourished, $29.7 \%$ were at risk of malnutrition and $61.7 \%$ were well nourished. Also another study by Kucuk \& Kapucu, (2017) who carried out malnutrition in elderly staying in nursing homes, and found that participants had malnutrition risk of $44.5 \%$ and a malnutrition incidence of $28.6 \%$. In comparison to studies conducted among older persons in the current study were less likely to be malnourished. This may be due to the extended family support involved in their nutritional care.

Regarding weight loss in the last three months, the results of the current study revealed that about half of elderly suffered from weight loss in the last three months. This result contradicted to the result of a study done by Ribeiro \& Rosa, (2015) that carried out malnutrition and associated variables in an elderly population of Criciúma and reported that about one third of elderly suffered from weight loss in the last three months. This contrast may be related to differences in economic levels between the two countries and this weight loss in the last three months may be due to lack of food resources, the absence of people who share elderly in eating. This reflects on elderly desire to eat or may be as a result of institutionalization or may indicate acute disease in the last period that causes this sudden weight loss.

\section{Conclusion}

The study concluded that the elderly with chronic disease are at risk for malnutrition with significant relation between mini-nutritional assessment scale and different chronic diseases 


\section{Recommendations}

The study recommended that:

- Further studies about the relation between nutritional status and chronic diseases among elderly should be implemented for generalization of the research findings.

- Establish periodically nutritional assessment of elderly to identify at risk by using MiniNutritional Assessment scale as a simple and firm screening tool.

- Paying more attention regarding nutritional needs of the elderly should be provided to improve the health of elderly.

- Develop continuous health education program for elderly and their caregiver about nutritional need specifically for elderly with chronic diseases.

\section{References}

1. Abdelrahman H., \& Elawam E., (2014): Nutritional status in community dwelling older population in an Egyptian urban area. J Aging Res Clin Pract.; 3(3):137-43.

2. Abdelrahman T., Mahfouz E., \& Mohammed E., (2012): Prevalence and comorbidities of overweight and obesity among elderly population residing a rural community, Minia, Egypt . The Egyptian journal of community medicine.; 30(4):59-69.

3. Abdelwahed A., Algameel M., \& Tayel D., (2018): Effect of a Nutritional Education Program on Nutritional Status of Elderly in Rural Areas of Damanhur City, Egypt, International Journal of Nursing Science; 8(5): 83-92.

4. Bangkok T., (2019): International Conference on Geriatrics and Ageing, December 09-10, 2019 Bangkok, Thailand Theme: Geriatric Health Care And Healthy Ageing In Current Life Style. https://geriatricsageing.expertconferences.org/

5. Skokowska B., Bączyk G., Dyk D., \& Miechowicz I., (2015): Relation between nutritional status of surgically treated elderly patients and selected chronic diseases, Probl Hig Epidemiol.; 96(1): 199-204

6. Charlson M., Pompei P., Ales K., \& MacKenzie C., (1987) A new method of classifying prognostic comorbidity in longitudinal studies: development and validation. J Chron Dis.;40(5):373-383. doi: 10.1016/0021-9681(87)90171-

7. Damayanthi H., Moy F., Abdullah K., \& Dharmaratne S., (2018): Prevalence of malnutrition and associated factors among community-dwelling older persons in Sri Lanka: a cross-sectional study, BMC Geriatrics (2018) 18:199

8. Eldardery N., Mo'awad E., \& Fouad N., (2018): Risk Factors of Malnutrition among Elderly in Geriatric Homes, IOSR Journal of Nursing and Health Science (IOSR-JNHS), Volume 7, Issue 5Ver. III., PP: 62-74.

9. Ghimire S., BaralB K., \& Callahan K., (2017): Nutritional assessment of communitydwelling older adults in rural Nepal. PLoS ONE; 12(2):1720-52.

10. Jung S., Bishop A., \& Lawrence J., (2017): Nutritional Status of Rural Older Adults is Linked to Physical and Emotional Health, J AcadNutr Diet. ; 117(6): 851-858.

11. Khater M., \& Abouelezz N., (2011): Nutritional status in older adults with mild cognitive impairment living in elderly homes in Cairo, Egypt, The Journal of Nutrition, Health \& Aging; 15(2):103-105.

12. Kucuk E., \& Kapucu S., (2017): Malnutrition in Elderly Staying in Nursing Homes, Konuralp Tip Dergisi; 9 (3):46-51.

13. Kucukerdonmez O., NavruzVarli S., \& Koksal E., (2017): Comparison of nutritional status in the elderly according to living situations, J Nutr Health Aging; 21(1):

14. LaBrier A., Corish C., \& Dwyer J., (2017): Nutrition in Older Adults, public Health Nutrition, edited by Judith L. Buttriss, et al., John Wiley \& Sons, Incorporated, ProQuestEbook Central, http://ebookcentral.proquest.com/lib/ucd/detail .action?docID $=4838300$.

15. Mahfouz E., Mohammed E., \& Abd ElRhman T., (2013): assessment of nutritional status of elderly populations in rural Minia, Egypt, journal of aging research \& clinical practice; 2: (3).

16. Ministry of Health and Population, (2017): Nutrition agenda for action a policy paper on scaling up nutrition interventions in Egypt, Cairo, 2017. Available at https://www.unicef.org/egypt/media/

17. Ojo O., (2019): Nutrition and Chronic Conditions, Nutrients, 11, 459; doi:10.3390/nu11020459

18. Ribeiro R., \& Rosa M., (2015): Early Recognition of Malnutrition in the Older Adult, A Quality Improvement Project Using a Standardized Nutritional Tool, 1-11. https://doi.org/10.1080/07370016.2015.99165 8

19. Rubenstein L., Harker J., Salvà A., Guigoz Y., and Vellas B., (2001): Screening for under 
nutrition in geriatric practice: developing the short-form mini-nutritional assessment (MNASF).J Gerontol A Biol Sci Med Sci. 2001 Jun;56(6):M366-72

20. Schneeweiss S., Wang P., Avorn J., \& Glynn R., (2003), Improved Comorbidity Adjustment for Predicting Mortality in Medicare Populations Health Serv Res. Aug; 38(4): $\quad 1103-1120$. doi: $10.1111 / 1475$ 6773.00165

21. Shahabi R., Jovein A., \& Asl N., (2019): Nutritional Status of the Elderly Living in Nursing Homes in Sabzevar, Iran, Journal of Clinical and Basic Research (JCBR) ; 3(1)1822

22. Shaheen H., Badr S., \& Saleh E., (2017): Comparative study between elderly with medical problems living in endwelling houses and with families in Banha City, Menoufia Medical Journal; 30:44-50.

23. Shebl A., Hatata E., Boughdady A., and ElSayed S., (2015): Prevalence and Risk Factors of Obesity among Elderly attending Geriatric Outpatient Clinics in Mansoura City, Journal of Education and Practice; 6 (30).

24. Shlisky J., Bloom D., Beaudreault A., Tucker K., Keller H., Freund-Levi Y., Fielding R., Cheng F., Jensen G., Wu D., \& Meydani S., (2017): Nutritional Considerations for Healthy Aging and Reduction in Age-Related Chronic Disease, journal of Adv Nutr. 17;8(1):17-26. doi: 10.3945/an.116.013474.

25. Tamang M., Yada U., Hosseinzadeh H., Kafle B., \& et al., (2019): Nutritional assessment and factors associated with malnutrition among the elderly population of Nepal: a cross-sectional study, BMC Research Notes; 12:246.

26. Turconi G., (2011): Healthy Aging: Nutritional Intervention to Improve and Extend Quality of Life among Older People, Journal of Nutrition \& Food Sciences; 1:(1) 1000e101.do 10.4172/2155-9600.1000e101

27. Volkert D., Beck M., Cederholm T., et al., (2019): ESPEN guideline on clinical nutrition and hydration in geriatrics, Clinical Nutrition, 38: 10-47.

28. Wilma L., \& Hankey C., (2015): Aging, Nutritional Status and Health. Healthcare; 3:648-58.
29. World Health Organization (WHO), (2018):

Diabetes. 2018. Available online: https://www.who.int/news-room/ factsheets/detail/diabetes. 